\title{
Emotional arousal and self-efficacy and their relation to match's results some of the players Racket Sports Games "Dr/ Tarek Mohamed Khalil elgmmal
}

\section{Introduction Search:}

Racquet sports games are the players ' tool (Racquet)) of each (Hockey - Tennis Table Tennis)as an important segment of players users means and tools during the performance and technical skills in many actual positions for training and matches.

The as the rest of sports psychology and other sciences that relate to the educational domain athletic growing and sustained interest by

researchers note as important to achieve excellence in athletic performance that comes on top of Sciences On the success of the Trainer and the development of athletic performance of the players, and emotional arousal is one of the basic psychological agitation task that affect their responses on the accuracy and skill performance which did not explained the correct way Help the player in control of his thoughts and focus his attention and control emotions and not to excess tension or fear of competition, the nature of the training and what owned by the player From the preparation myself well qualifies. (1:161)

to face the emotional by instigating that may hinder the performance of skills and affect the outcome of the team, we find this clear to the players Racquet Sports Games. When influenced by negative attitudes during a match they lose their nerves as a result of high arousal that occur as a result of the weakness of their experience in Emotional arousal control during sudden situations causing weakness in skill and tactical performance of the player.(10:438)

As this type of psyche arousal is an important factor in the direct influence during the performance of the players Racquet sports games such as individual or collective scoring during maneuvers or skill or deception and which Require the player make his decision quickly and the performance of high-of accuracy, calm and concentration level Attention to get a good performance can achieve what cost do these

Assistant Professor, Department of Games - Faculty of Physical Education University of Sadat City 
players from the requirements and duties.(3:125)

The high degree of emotional by instigating the player to the level necessary for the good performance of the athlete that requires a synergy the good players thus generating the performance of skills useful and effective for the whole team.

So the psychological preparation good player positioned to face the emotional arousal that may hinder the performance of skills and affects the outcome of the team, we find this clear to players Racquet Sports Games.

When influenced by negative attitudes during a match are losing their nerves as a result of high arousal that may occur as a result of the weakness of their experience to the lack of control during sudden attitudes arousal Causing weakness in skill and tactical performance of the player so doing, have difficulty in finding a balance between the run of play.

What the player displays sometimes elevated to arousal the affirmative or negative and thus the impact of this reflected on the performance skills of the player. $(2: 133)$

Compared with a variation in the relationship between the players and Racquet sports games divergence kinds of tools and the types of skills used and the nature of and the proportion of direct contact or not during the actual positions of the matches.

Refers (Abdul Wahab Mohammed al-Najjar) 1999 to arousal as a physiological process psyche - vary in intensity and the degree requirement, according to the player and psychomotor skills in training and competition performance.

Arousal touted as the activation for members and mechanisms the body that sunders the control of the autonomic nervous system, while degree bathes fundamental relationship between arousal and performance Player Skills at any level to specific nature take the form of the following equation: Performance = arousal $\times$ skill level. $(8: 122)$

While Qassim Hassan Hussein in 1998 indicates that most of the players tend to estimate the value of themselves and their 
personality through the level of their athletic performance, they identify themselves as much as the value of their athletic performance improves. (9:432) Here we must emphasize the importance of the player on the wrong aspects of performance recognize, sometimes mistakes are associated with the link between the level of athletic performance as a kind of Oriented to the same person and to reduce and then that of value for himself. (6:45)

Since the effectiveness of self-help guide the player purposeful behavior as the rise in the level of self-efficacy with the player Depends on its ability to benefit from past experience, it also is a key factor that increases the individual's confidence in itself, and where it includes organization of emotion. (12:114)

Changes in behavioral and psychological responses and experiences are supposed to player's racquet sports games differ in degree Which seem reactions Reactivity (toward environmental stimulation or excitement for training or match for each sport by the nature of the sport and friction player during the competition and that both the nervous system and behavioral responses contribute to these differences in the reaction. While self-skill types of self, which is an expression of the individual means those enjoyed by the private kinetics skills as a game and the efficiency the preparations for the various motor skills which a whole constitute basic motor skills in that game. $(12: 114) \cdot(11: 224)$

Having the player of this quality generated through continuity in the correct and successful attempts to gain experience by participating in competition and there are also factors that impact extent of self-efficacy and skill are the performance and achievements of verbal persuasion and physiological status and alternative experience.

\section{Research problem:}

Players are exposed to some external psychosocial pressures trainer and fans in various positions within the matches, this results in a kind of emotional arousal to the player during the game, and leads to the loss of many of the precision and calm and focus attention in performance skills, has also been going through the players some psychological 
negative attitudes such as tension and fear and anxiety and volatility in performance result of various emotional attitudes firming the matches as well as the presence of the challenge and excitement and emotional arousal, which may result in loss of points selfefficacy appears to anticipate the players for their performance and their best effort to cope with attitudes and difficulties that they face within the matches.6

$$
\text { Based upon the }
$$
researcher believes that Selfefficacy and its relation to of the self and its relationship Emotional arousal of these players have great significance when affected by the negative attitudes during a match and lose their nerves as a result of high arousal that occurs as a result of the weakness of their experience arousal in control during emotionality attitudes causing sudden weakness in the skill and tactical player performance where they face difficulty in finding a balance between the run of play and between the level of performance requirements and the level of intensity of arousal, this is due to the difficulty and skill requirements in Racquet
Sports Games an important determinant of energy in the study of the relationship between the severity of arousal and the level of performance as the extent of the appropriate arousal to Achievement of performance successful in complex and difficult skills

This requires achievement a lot of energy and has a relatively tight range arousal and increases with long insert skill in the direction of ease. So support the idea of studying the relationship between arousal and motor performance and the level of skill performance as a result of the difficulty of the skill, especially for activities or games that practice bat Sports and Games Racquet.

So it is through this research work research tends to study the nature of the relationship between the level of emotional arousal and selfphysical and skill players Racquet Sports Games level.

As well as that according to the nature of the relationship of this study can detect negative situations and internal psychological factors that exposed players Racquet sports games within games weak arousal and to decline and the 
high of the level required by the nature of attitudes in the matches for the sports Racquet games and how to guide the player to control it and make it effective in order to check the performance of skills good for the whole team.

So the researcher aims to identify the level Emotional arousal trailers (negative positive) and the level of "selfefficacy" in dealing with the disorders and the relationship of that to the players-fixing Racquet sports games.

\section{Used search terms:}

Received in the current research following terms:

Defined Awatef Saleh, (1993): self-efficacy as "an individual's ability to perform the behavior that achieves the desired results in a certain position and control the events that affect their lives and the issuance of Self-expectations of how the tasks and activities carried out by the individual performance and effort required predicting the amplitude of and perseverance to achieve this activity or work Self-efficacy.(8: 46 )

(Bandura) known as Pandora, 1986: self-efficacy as a "people's assessment of their ability to execute and organize a series of events required to get a clear types of performance".(14:109)

Bandura \& Wood as defined by the (Pandora-Wood, 1989: 805) as "confidence in the abilities of the individual to trigger motivation and cognitive resources and a series of regularly required to meet the requirements of the position events. (15:191)

The provisions of the individual or his expectations for his performance in the attitudes of behavior are ambiguous and reflected these expectations on the choice of activities included in the performance and the effort and face the difficulties and accomplish behavior. (13:191) They are emotional arousal "is a state characterized by hard work and a desire to certain behavior. (5:59)

Emotional arousal: it's individual's response to the environment and be closely linked strongly behavior. (4:272)

\section{Research goals:}

1- To identify degree of emotional arousal to the players some Racquet games (Hockey- Tennis- Table Tennis). 
2- To identify the degree of self-efficacy (physical - and skill) with the players some Racquet games (Hockey Tennis - Table Tennis).

3- To identify differences in the degree of emotional arousal between the players some Racquet games (Hockey Tennis - Table Tennis).

4- To identify the differences in the degree of self-efficacy (physical - and skill) between the players some Racquet games (Hockey - Tennis Table Tennis).

5- To identify the relationship between emotional arousal and self-efficacy on the results of the matches among players some Racquet games (Hockey - Tennis - Table Tennis).

\section{Research questions:}

1- What is the degree of emotional arousal to the players some Racquet games (hockey - tennis - table tennis)? 2- What is the degree of selfefficacy (physical - and skill) with the players some Racquet games (hockey - tennis - table tennis)?

3- Are there differences in the degree of emotional arousal between the players some
Racquet games (hockey- tennis - table tennis).

4- Are there differences in the degree of self-efficacy (physical - and skill) between the players some Racquet games (hockey - tennis - table tennis)?

5- What is the relationship between emotional arousal and self-efficacy and the results of the matches among players some Racquet games (hockey tennis - table tennis)?

\section{Search Procedures}

Research Methodology:

This research is a research concerned with understanding the relationships described the psychological phenomena for some players racket games have adopted the researcher to describe the relationship between arousal emotionality and effective self on the survey method as a tool to collect data, and methodology descriptive to interpret the relations as the descriptive approach does not stop at the data collection and tabulation but it goes beyond that to access the link between relationships, description and interpretation. 
Community and the research sample:

Represents Community

Search some of the players Racket Games born in 1999/2000 to sports (hockey, tennis, table tennis,) and included a sample basic research and exploratory at (122) of them ( 87) players of the basic sample for Games Racket players selected purposively of them Total (51) players for hockey, (41) players for the sport of tennis, in addition to (30) for the sport of table tennis

The research sample consisted of player's racket games during the competitions each team of sports under consideration on my own for the participants in the sports season 2012- 2013. (Annex to 5)

It was excluded four players for non-completion of the answer to all the questions and the occurrence of errors in the answers as shown schedule(1). The research sample:

Table (1)

The distribution numerical research sample (exploratory - Basic).

\begin{tabular}{|c|c|c|c|}
\hline$\frac{\text { Sample }}{\text { Activity }}$ & Exploratory & Basic & Total \\
\hline Hockey & 15 & 36 & 51 \\
\hline Tennis & 11 & 30 & 41 \\
\hline Table tennis & 9 & 21 & 30 \\
\hline total & 35 & 87 & 122 \\
\hline
\end{tabular}

The homogeneity of research sample:

To be sure of a research sample under the curve equinoctial, the researcher conducted homogeneity between the research sample in the following variables: (age, height, weight, age training( This is also shown in schedule (2) 
Table (2)

Statistical description (Hockey -Tennis - Table Tennis)

Research sample in some growth variables (Age - Height - Weight

- old training) $\mathrm{N}=87$

\begin{tabular}{|c|c|c|c|c|c|c|c|c|}
\hline $\begin{array}{l}\text { Variables } \\
\text { in the } \\
\text { search } \\
\end{array}$ & \multicolumn{2}{|c|}{$\begin{array}{l}\text { The unit of } \\
\text { measurement }\end{array}$} & Sample & number & Average & Intermediat & $\begin{array}{c}\text { The } \\
\text { standard } \\
\text { deviation }\end{array}$ & Convolution \\
\hline \multirow{3}{*}{ The age } & \multirow{3}{*}{\multicolumn{2}{|c|}{ the year }} & Hockey & 36 & 15.58 & 16.00 & 0.50 & -0.353 \\
\hline & & & Tennis & 30 & 15.56 & 16.00 & 0.51 & -0.283 \\
\hline & & & $\begin{array}{l}\text { Table } \\
\text { Tennis }\end{array}$ & 21 & 15.61 & 16.00 & 0.49 & -0.529 \\
\hline \multirow{3}{*}{ Length } & \multirow{3}{*}{\multicolumn{2}{|c|}{ Centimeter }} & $\overline{\text { Hockey }}$ & 36 & 160.08 & 160.00 & 2.77 & -0.125 \\
\hline & & & Tennis & 30 & 159.77 & 160.00 & 2.84 & 0.059 \\
\hline & & & $\begin{array}{l}\text { Table } \\
\text { Tennis }\end{array}$ & 21 & 160.33 & 16.00 & 2.76 & 0.229 \\
\hline \multirow{3}{*}{ Weight } & \multirow{3}{*}{\multicolumn{2}{|c|}{ Kilogram }} & Hockey & 36 & 50.39 & 50.50 & 1.86 & $\begin{array}{l}-0.070 \\
\end{array}$ \\
\hline & & & Tennis & 30 & 50.36 & 51.00 & 2.01 & -0.51 \\
\hline & & & $\begin{array}{l}\text { Table } \\
\text { Tennis }\end{array}$ & 21 & 50.57 & 51.00 & 2.29 & -0.267 \\
\hline \multirow{3}{*}{$\begin{array}{l}\text { Age } \\
\text { Training }\end{array}$} & \multirow{3}{*}{\multicolumn{2}{|c|}{ the year }} & Hockey & 36 & 4.47 & 4.00 & 0.88 & 0.224 \\
\hline & & & Tennis & 30 & 4.33 & 4.00 & 0.80 & 0.159 \\
\hline & & & $\begin{array}{l}\text { Table } \\
\text { Tennis }\end{array}$ & 21 & 4.52 & 4.00 & 0.75 & 0.305 \\
\hline \multicolumn{9}{|c|}{ 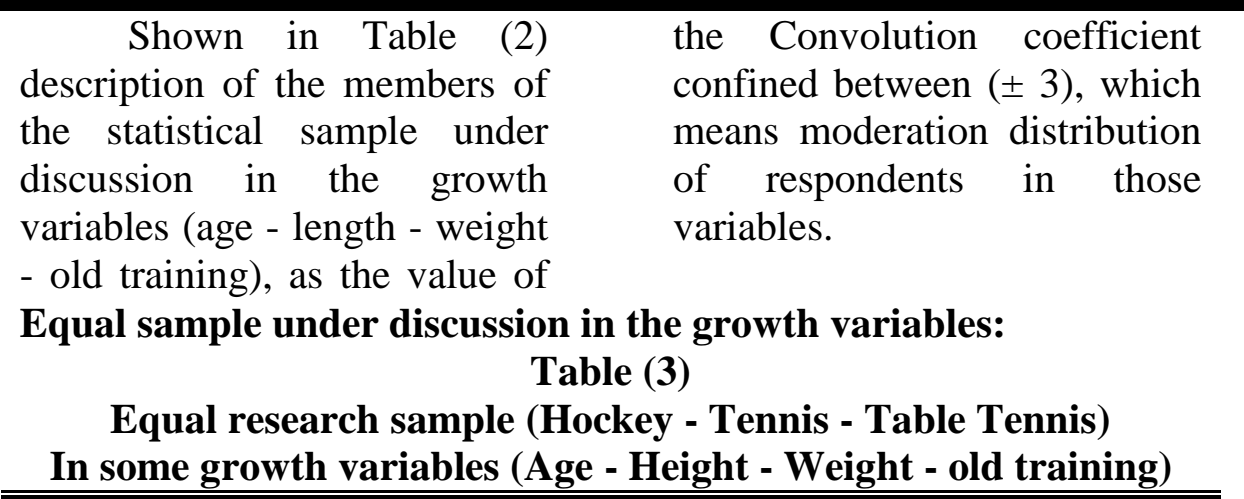 } \\
\hline $\begin{array}{l}\text { Variab } \\
\text { the se }\end{array}$ & $\begin{array}{l}\text { les in } \\
\operatorname{arch}\end{array}$ & & $\begin{array}{l}\text { ontrast } \\
\text { ource }\end{array}$ & & $\begin{array}{l}\text { rees of } \\
\text { edom }\end{array}$ & $\begin{array}{l}\text { Sum of } \\
\text { squares }\end{array}$ & $\begin{array}{l}\text { Average } \\
\text { squares }\end{array}$ & $\begin{array}{l}\text { The value } \\
\text { of " } \mathbf{F} "\end{array}$ \\
\hline \multirow{3}{*}{\multicolumn{2}{|c|}{ The age }} & Betw & een grou & & 2 & 0.034 & 0.017 & \multirow{3}{*}{0.069} \\
\hline & & Witl & in group & & 84 & 21.069 & 0.251 & \\
\hline & & & ummati & & 86 & 12.103 & & \\
\hline
\end{tabular}


Follow Table (3)

Equal research sample (Hockey - Tennis - Table Tennis)

In some growth variables (Age - Height - Weight - old training)

\begin{tabular}{|c|c|c|c|c|c|}
\hline $\begin{array}{l}\text { Variables in } \\
\text { the search }\end{array}$ & $\begin{array}{c}\text { Contrast } \\
\text { source }\end{array}$ & $\begin{array}{c}\text { Degrees of } \\
\text { freedom }\end{array}$ & $\begin{array}{l}\text { Sum of } \\
\text { squares }\end{array}$ & $\begin{array}{l}\text { Average } \\
\text { squares }\end{array}$ & $\begin{array}{l}\text { The value } \\
\text { of " } F \text { " }\end{array}$ \\
\hline \multirow{3}{*}{ Length } & Between groups & 2 & 4.113 & 2.057 & \multirow{3}{*}{0.264} \\
\hline & Within groups & 84 & 654.783 & 7.795 & \\
\hline & total summation & 86 & 658.897 & & \\
\hline \multirow{3}{*}{ Weight } & Between groups & 2 & 0.599 & 0.300 & \multirow{3}{*}{0.073} \\
\hline & Within groups & 84 & 342.665 & 4.079 & \\
\hline & total summation & 86 & 343.264 & & \\
\hline \multirow{3}{*}{ Age Training } & Between groups & 2 & 0.525 & 0.263 & \multirow{3}{*}{0.388} \\
\hline & Within groups & 84 & 56.877 & 0.677 & \\
\hline & total summation & 86 & 57.402 & & \\
\hline
\end{tabular}

The value of " $F$ " spreadsheet at a level of significance $(0.05)$ and the degree of freedom (2.84).

Seen from the table (3) that there is statistically significant differences between the three research groups (hockey - tennis - table tennis) in some growth variables in

Question, which shows the Equalization of groups in those Variables.

\section{The basic experiment} research:

$$
\text { The }
$$

researcher

distributes

measurements

questionnaires on the players involved in the sports season 2012- $2013 \mathrm{~m}$ before the matches in the period 5 13.07.2013 and also tournament in the period of 8 $10 / 9 / 2013$ hockey, and from 2-9 / 9/2013 for the sport of table tennis, and in the period from 24-29 / 9/2013 for the sport of tennis under discussion, which was held as competitions tables an hour before the start of the games for each sport separately and totaling in total sample of basic research for Racket Games (87) player, after the completion of the answer to the paragraphs of measurements, the researcher collected questionnaires and after the establishment of the matches 
according to the attached tables (Annex 5) According to the results of the matches, recording the winning players from first to last place by Translations of results shown during the tournament each team of the sports under consideration individually, The researcher calculates the measurement results of the research sample by giving each case to win all The matches for each team in the (hockey), and every player in the (tennis, table tennis) in competitions under consideration (three points), and in the case of a tie (points), loss (zero ) considering that as a result of self-significance for each player of the matches (tennis, table tennis) and the significance of the team of hockey players in competitions under consideration, If one of the players and teams won two matches and lost in the third match, which lead to his release from the tournament, it collects (6) points, but if the player or the team won all their matches in the tournament. When it is collected the number of matches won in the multiplication (three points) to be collect the number of player points in the final evaluation of the results, in the sense that it has been calculating the number of matches to win for each player or team in the multiplication (three points) for the number of points are collected the player of the results under consideration, After the registration of responses to the standards by the players and collect questionnaires, the total score calculated for each player on each scale individually and after the matches were restriction scores points match results for each sport sports racket games values (Hockey Tennis - Table Tennis), it has been subjected Evaluate the results of the matches and the values of their answers to the measurements of statistical analysis and discharged to conduct statistical methods spss program to obtain search results and achieve its objectives system.

Presentation and discussion of the results: 
Table (4)

The statistical Description of some players Racquet games

In the level of emotional arousal, according to the type of activity

\begin{tabular}{|c|c|c|c|c|c|c|}
\hline variable & $\begin{array}{c}\text { unit } \\
\text { Measurement }\end{array}$ & Activity & number & $\begin{array}{c}\text { The } \\
\text { arithmetic } \\
\text { average }\end{array}$ & $\begin{array}{l}\text { standard } \\
\text { deviation }\end{array}$ & $\begin{array}{l}\text { Sprains } \\
\text { modulus }\end{array}$ \\
\hline \multirow{3}{*}{$\begin{array}{l}\text { emotional } \\
\text { arousal }\end{array}$} & \multirow{3}{*}{ Grade } & Hockey & 36 & 123.89 & 9.24 & 0.929 \\
\hline & & Tennis & 30 & 101.80 & 6.56 & 0.086 \\
\hline & & $\begin{array}{l}\text { Table } \\
\text { Tennis }\end{array}$ & 21 & 81.48 & 6.65 & -0.903 \\
\hline \multirow{3}{*}{$\begin{array}{c}\text { (Competition } \\
\text { behavior( }\end{array}$} & \multirow{3}{*}{ Grade } & Hockey & 36 & 106.28 & 1.43 & -0.335 \\
\hline & & Tennis & 30 & 99.27 & 0.525 & -0.369 \\
\hline & & $\begin{array}{l}\text { Table } \\
\text { Tennis }\end{array}$ & 21 & 84.76 & 3.73 & 0.039 \\
\hline
\end{tabular}

Seen from the table (4) that the average order of by instigating emotional for my players tennis games under consideration according to the type of activity came to hockey players and tennis and finally table tennis, respectively, in descending order (123.89) (101.80) (81.48), as evidenced

\section{Table (5)}

The statistical Description players Some Racquet games In the self-concept (physical - skill) according to the type ofactivity

\begin{tabular}{c|c|c|c|c|c|c}
\hline \hline variable & $\begin{array}{c}\text { Unit } \\
\text { Measurement }\end{array}$ & Activity & number & $\begin{array}{c}\text { The } \\
\text { arithmetic } \\
\text { average }\end{array}$ & $\begin{array}{c}\text { standard } \\
\text { deviation }\end{array}$ & $\begin{array}{c}\text { Sprains } \\
\text { modulus }\end{array}$ \\
\hline \hline \multirow{2}{*}{$\begin{array}{c}\text { Self- } \\
\text { efficacy } \\
\text { physical }\end{array}$} & \multirow{2}{*}{ Grade } & Hockey & 36 & 56.81 & 2.12 & -0.205 \\
\cline { 3 - 7 } & Tennis & 30 & 63.10 & 4.41 & 1.140 \\
\cline { 3 - 7 } & $\begin{array}{c}\text { Table } \\
\text { Tennis }\end{array}$ & 21 & 50.19 & 3.33 & -1.707 \\
\hline \hline \multirow{2}{*}{$\begin{array}{c}\text { Self- } \\
\text { efficacy } \\
\text { skills }\end{array}$} & \multirow{2}{*}{ Grade } & Hockey & 36 & 89.53 & 1.42 & -1.159 \\
\cline { 3 - 7 } & Tennis & 30 & 95.07 & 3.58 & 1.197 \\
\cline { 3 - 7 } & $\begin{array}{c}\text { Table } \\
\text { Tennis }\end{array}$ & 21 & 84.14 & 2.52 & -2.011 \\
\hline \hline
\end{tabular}


Seen from the table (5) that the average order of physical self for the effectiveness of my players tennis games under consideration according to the type of activity came to tennis players Ground then hockey and finally table tennis, respectively, in descending order (63.10), (56.81), (50.19), as evidenced by the same table the average order of selfefficacy skills for my players tennis games under consideration according to the type of activity came to tennis players then finally hockey and table tennis, respectively, in descending order (95.07, 89.53, 84.14).

Table (6)

Analysis of variance between the players some

Racquet games (Hockey - Tennis - Table Tennis) in emotional arousal

\begin{tabular}{|c|c|c|c|c|c|}
\hline $\begin{array}{l}\text { Variables } \\
\text { in the } \\
\text { search }\end{array}$ & $\begin{array}{c}\text { variance } \\
\text { source }\end{array}$ & $\begin{array}{c}\text { Degrees } \\
\text { of } \\
\text { freedom }\end{array}$ & $\begin{array}{l}\text { Sum of } \\
\text { squares }\end{array}$ & $\begin{array}{l}\text { Average } \\
\text { squares }\end{array}$ & $\begin{array}{c}\text { The } \\
\text { value } \\
\text { of } \\
\text { F }^{\prime \prime \prime \prime}\end{array}$ \\
\hline \multirow{3}{*}{$\begin{array}{l}\text { emotional } \\
\text { arousal }\end{array}$} & $\begin{array}{c}\begin{array}{c}\text { Between } \\
\text { groups }\end{array} \\
\end{array}$ & 2 & 482.982 & 241.491 & \multirow{3}{*}{$* 24.29$} \\
\hline & $\begin{array}{l}\text { Within } \\
\text { groups }\end{array}$ & 83 & 825.186 & 9.942 & \\
\hline & $\begin{array}{c}\text { total } \\
\text { summation }\end{array}$ & 85 & 1308.168 & & \\
\hline \multirow{3}{*}{$\begin{array}{c}\text { Competition } \\
\text { behavior }\end{array}$} & $\begin{array}{l}\text { Between } \\
\text { groups }\end{array}$ & 2 & 322.149 & 161.074 & \multirow{3}{*}{$* 19.43$} \\
\hline & $\begin{array}{l}\text { Within } \\
\text { groups }\end{array}$ & 83 & 688.070 & 8.290 & \\
\hline & $\begin{array}{c}\text { total } \\
\text { summation }\end{array}$ & 85 & 1010.219 & & \\
\hline
\end{tabular}

The value of " $F$ " spreadsheet at a level of significance $(0.05)$ and the degree of freedom $(\mathbf{2 . 8 3})$.

It is seen from the table

(6) that there are significant differences between the three research groups (Hockey -

Tennis - Table Tennis) in emotional by instigating variable. So will the researcher calculate the least significant 
difference (L.S.D) to get to know the direction of the difference in favor of any activity.

Table (7)

Significant differences between the averages

of the groups Research sample in emotional by instigating and

Behavior of the competition using the least significant difference scale (L.S.D) $\mathrm{N}=87$

\begin{tabular}{c|c|c|c|c|c|c}
\hline \hline $\begin{array}{c}\text { Variables in the } \\
\text { search }\end{array}$ & Activity & $\begin{array}{c}\text { Avera } \\
\text { ges }\end{array}$ & $\begin{array}{c}\text { Values } \\
\text { L.S.D }\end{array}$ & $\begin{array}{c}\text { Hock } \\
\text { ey }\end{array}$ & $\begin{array}{c}\text { Tenn } \\
\text { is }\end{array}$ & $\begin{array}{c}\text { Table } \\
\text { Tennis }\end{array}$ \\
\hline \hline \multirow{4}{*}{$\begin{array}{c}\text { emotional } \\
\text { arousal }\end{array}$} & Hockey & 123.89 & & & $* 22.0$ & $* 42.41$ \\
\cline { 2 - 3 } & Tennis & 101.80 & \multirow{2}{*}{4.26} & & & $* 20.32$ \\
\cline { 2 - 3 } \cline { 5 - 7 } & $\begin{array}{c}\text { Table } \\
\text { Tennis }\end{array}$ & 81.48 & & & & \\
\hline \hline \multirow{3}{*}{$\begin{array}{c}\text { Competition } \\
\text { behavior }\end{array}$} & Hockey & 106.28 & & & $* 7.01$ & $* 21.52$ \\
\cline { 2 - 3 } \cline { 5 - 7 } & Tennis & 99.27 & \multirow{2}{*}{3.88} & & & $* 14.51$ \\
\cline { 2 - 3 } \cline { 5 - 7 } & Table & 84.76 & & & & \\
\hline \hline
\end{tabular}

Seen from the table (7) There are significant differences between the mean Groups Find three (Hockey Tennis Ground - table tennis) in arousal emotional reaching their value (123.89) (101.80) (81.48), respectively salary from highest to lowest.

It also illustrated the presence of statistically significant differences between the averages of the three research groups (Hockey Tennis Ground - table tennis) in the conduct of the competition, reaching their value (106.28), (99.27),
(84.76), respectively salary from highest to lowest.

There are also significant differences between each of the three research groups (Hockey - Tennis table tennis) in each of emotional arousal and behavior of the competition are as follows: -

There are differences between the hockey players and tennis players in emotional arousal variable and in favor of the average grades for the hockey players.

There are differences between the hockey players 
and table tennis player in emotional arousal variable and in favor of the average grades for the hockey players.

There are differences between tennis players and table tennis in emotional arousal variable and in favor of the average grades for the tennis players.

There are differences between the hockey players and tennis players in the competition behavior of variable and in favor of the average grades for the hockey players.

There are differences between the hockey players and table tennis players in the competition behavior of the variable and in favor of the average grades for the hockey players.

There are differences between tennis players and table tennis competition in the behavior of the variable and in favor of the average grades for the tennis players.

Table (8)

Analysis of variance between the players some Racquet games (Hockey - Tennis - Table Tennis) in emotional arousal

\begin{tabular}{|c|c|c|c|c|c|}
\hline $\begin{array}{l}\text { Variables in } \\
\text { the search }\end{array}$ & $\begin{array}{l}\text { variance } \\
\text { source }\end{array}$ & $\begin{array}{c}\text { Degrees } \\
\text { of } \\
\text { freedom }\end{array}$ & $\begin{array}{l}\text { Sum of } \\
\text { squares }\end{array}$ & $\begin{array}{c}\text { Average } \\
\text { squares }\end{array}$ & $\begin{array}{c}\text { The } \\
\text { value } \\
\text { of } F^{\prime \prime \prime \prime}\end{array}$ \\
\hline \multirow{3}{*}{$\begin{array}{c}\text { Self-efficacy } \\
\text { physical }\end{array}$} & $\begin{array}{c}\text { Between } \\
\text { groups }\end{array}$ & 2 & 293.767 & 146.883 & \multirow{3}{*}{$* 14.608$} \\
\hline & $\begin{array}{l}\text { Within } \\
\text { groups }\end{array}$ & 83 & 834.565 & 10.055 & \\
\hline & $\begin{array}{c}\text { total } \\
\text { summation }\end{array}$ & 85 & 1128.332 & & \\
\hline \multirow{3}{*}{$\begin{array}{c}\text { Self-efficacy } \\
\text { skills }\end{array}$} & $\begin{array}{l}\text { Between } \\
\text { groups }\end{array}$ & 2 & 269.374 & 134.687 & \multirow{3}{*}{ *19.178 } \\
\hline & $\begin{array}{l}\text { Within } \\
\text { groups }\end{array}$ & 83 & 258.909 & 7.023 & \\
\hline & $\begin{array}{c}\text { total } \\
\text { summation }\end{array}$ & 85 & 852.283 & & \\
\hline
\end{tabular}

The value of "F" spreadsheet at a level of significance (0.05) and the degree of freedom (2.83). 
It is seen from the table (8) that there are significant differences between the three research groups (Hockey Tennis - table tennis) in the self-efficacy variable (physical
- skills). So will the researcher calculate the least significant difference (L.S.D) to get to know the direction of the difference in favor of any activity.

Table (9)

Significant differences between the mean Find the Three groups (Hockey - Tennis - Table Tennis) in physical Self-concept and technique using the least significant difference scale (L.S.D) $\mathbf{N}=87$

\begin{tabular}{|c|c|c|c|c|c|c|}
\hline $\begin{array}{l}\text { Variables in } \\
\text { the search }\end{array}$ & Activity & $\begin{array}{c}\text { the } \\
\text { averages }\end{array}$ & $\begin{array}{l}\text { Values } \\
\text { L.S.D }\end{array}$ & $\begin{array}{c}\text { Hock } \\
\text { ey }\end{array}$ & Tennis & $\begin{array}{l}\text { Table } \\
\text { Tennis }\end{array}$ \\
\hline \multirow{3}{*}{$\begin{array}{c}\text { Self-efficacy } \\
\text { physical }\end{array}$} & Hockey & 56.81 & \multirow{3}{*}{3.62} & & $* 6.29$ & $* 6.62$ \\
\hline & Tennis & 63.10 & & & & *12.91 \\
\hline & $\begin{array}{l}\text { Table } \\
\text { Tennis }\end{array}$ & 50.19 & & & & \\
\hline \multirow{3}{*}{$\begin{array}{c}\text { Self-efficacy } \\
\text { skills }\end{array}$} & Hockey & 89.53 & \multirow{3}{*}{2.98} & & $* 5.54$ & $* 5.39$ \\
\hline & Tennis & 95.07 & & & & $* 10.93$ \\
\hline & $\begin{array}{l}\text { Table } \\
\text { Tennis }\end{array}$ & 84.14 & & & & \\
\hline
\end{tabular}

Seen from the table (21) There are significant differences between the mean Groups Find three (Hockey Tennis - table tennis) in the self-physical effectiveness of reaching their value (56.81), (63.10), (50.19), respectively salary from highest to lowest.

It also illustrated the presence of statistically significant differences between the averages of the three research groups (Hockey - Tennis table tennis) in the skills of self-efficacy, reaching their value (89.53), (95.07), (84.14), respectively.

There are also significant differences between each of the three research groups (Hockey - Tennis table tennis) in each of the physical self-concept and selfefficacy skills which are as follows: - There are differences between the hockey players and tennis players in the physical self-efficacy variable 
for the benefit of the average grades for the tennis players. There are differences between the hockey players and table tennis players in the physical self-concept of variable and in favor of the average grades for the hockey players.

There are differences between tennis players and table tennis in physical selfefficacy variable for the benefit of the average grades for the tennis players.

There are differences between the hockey players and tennis players in physical self-efficacy variable for the benefit of the average grades for the tennis players.

There are differences between the hockey players and table tennis players in the skills of self-efficacy variable for the benefit of the average grades for the hockey players.

There are differences between tennis players and table tennis skills in self-efficacy variable for the benefit of the average grades for the tennis players.

Table (10)

Matrix correlation between emotional arousal

And self-efficacy and the results of the matches among hockey players $N=36$

\begin{tabular}{|c|c|c|c|c|c|c|}
\hline \multirow{2}{*}{\multicolumn{2}{|c|}{ Variables in the search }} & \multicolumn{2}{|c|}{ motional arousal } & \multicolumn{2}{|c|}{ Self-efficacy } & \multirow{2}{*}{$\begin{array}{c}\text { results } \\
\text { of the } \\
\text { matches }\end{array}$} \\
\hline & & emotional & Competition & nhysical & skills & \\
\hline \multirow{2}{*}{$\begin{array}{l}\text { emotional } \\
\text { arousal }\end{array}$} & $\begin{array}{c}\text { emotional } \\
\text { arousal }\end{array}$ & & 0.635 & 0.678 & 0.711 & 0.643 \\
\hline & $\begin{array}{c}\text { Competition } \\
\text { behavior }\end{array}$ & & & 0.692 & 0.644 & 0.702 \\
\hline \multirow{2}{*}{$\begin{array}{l}\text { Self- } \\
\text { efficacy }\end{array}$} & $\begin{array}{c}\text { Self-efficacy } \\
\text { physical }\end{array}$ & & & & 0.713 & 0.721 \\
\hline & $\begin{array}{c}\text { Self-efficacy } \\
\text { Skills }\end{array}$ & & & & & 0.737 \\
\hline \multicolumn{2}{|c|}{ results of the matches } & & & & & \\
\hline
\end{tabular}

The value of " $\mathrm{t}$ " Driven at $(0,05)=0.325$

Seen from the table (22)

and the presence of $\mathrm{D}$. statistical correlation at level (0.05) between the psychological variables under consideration (emotional arousal and behavior of competition and self-efficacy and physical skills) and the results of the matches among hockey players. 
Table (11)

Matrix correlation between emotional arousal by instigating And self-efficacy and the results of the matches for tennis players $\mathbf{N}=\mathbf{3 0}$

\begin{tabular}{|c|c|c|c|c|c|c|}
\hline \multirow{2}{*}{\multicolumn{2}{|c|}{ Variables in the search }} & \multicolumn{2}{|c|}{ motional arousal } & \multicolumn{2}{|c|}{ Self-efficacy } & \multirow{3}{*}{$\begin{array}{c}\begin{array}{c}\text { results } \\
\text { of the } \\
\text { matches }\end{array} \\
0.707\end{array}$} \\
\hline & & \multirow{2}{*}{$\begin{array}{c}\text { emotional } \\
\text { arousal }\end{array}$} & \multirow{2}{*}{$\begin{array}{c}\begin{array}{c}\text { Competition } \\
\text { behavior }\end{array} \\
0.703\end{array}$} & \multirow{2}{*}{$\frac{\text { physical }}{0.691}$} & \multirow{2}{*}{$\frac{\text { skills }}{20.698}$} & \\
\hline \multirow{2}{*}{$\begin{array}{l}\text { emotional } \\
\text { arousal }\end{array}$} & $\begin{array}{l}\text { emotional } \\
\text { arousal }\end{array}$ & & & & & \\
\hline & $\begin{array}{c}\text { Competition } \\
\text { behavior }\end{array}$ & & & 0.589 & 0.600 & 0.616 \\
\hline \multirow{2}{*}{$\begin{array}{l}\text { Self- } \\
\text { efficacy }\end{array}$} & $\begin{array}{c}\text { Self-efficacy } \\
\text { physical }\end{array}$ & & & & 0.645 & 0.699 \\
\hline & $\begin{array}{c}\text { Self-efficacy } \\
\text { Skills }\end{array}$ & & & & & 0.709 \\
\hline \multicolumn{2}{|c|}{ results of the matches } & & & & & \\
\hline
\end{tabular}

The value of "t" Tabulated at $(0,05)=0.361$

Seen from the table (23)

and the presence of $\mathrm{D}$. statistical correlation at level (0.05) between the psychological variables under consideration

(emotional arousal and behavior of competition and self-efficacy and physical skills) and the results of the matches among tennis players

\section{Table (12)}

Matrix correlation between emotional arousal and Self-efficacy and the results of matches the table tennis players $N=21$

\begin{tabular}{|c|c|c|c|c|c|c|}
\hline \multirow{2}{*}{\multicolumn{2}{|c|}{ Variables in the search }} & \multicolumn{2}{|c|}{ motional arousal } & \multicolumn{2}{|c|}{ Self-efficacy } & \multirow{3}{*}{$\begin{array}{c}\begin{array}{c}\text { results } \\
\text { of the } \\
\text { matches }\end{array} \\
0.654\end{array}$} \\
\hline & & \multirow{2}{*}{$\begin{array}{c}\text { emotional } \\
\text { arousal }\end{array}$} & \multirow{2}{*}{$\begin{array}{c}\begin{array}{c}\text { Competition } \\
\text { behavior }\end{array} \\
0.728\end{array}$} & \multirow{2}{*}{$\begin{array}{c}\text { physical } \\
0.582\end{array}$} & \multirow{2}{*}{ skills } & \\
\hline \multirow{2}{*}{$\begin{array}{l}\text { emotional } \\
\text { arousal }\end{array}$} & $\begin{array}{c}\text { emotional } \\
\text { arousal }\end{array}$ & & & & & \\
\hline & $\begin{array}{c}\text { Competition } \\
\text { behavior }\end{array}$ & & & 0.647 & 0.696 & 0.701 \\
\hline \multirow{2}{*}{$\begin{array}{l}\text { Self- } \\
\text { efficacy }\end{array}$} & $\begin{array}{c}\text { Self-efficacy } \\
\text { physical }\end{array}$ & & & & 0.753 & 0.683 \\
\hline & $\begin{array}{c}\text { Self-efficacy } \\
\text { Skills } \\
\end{array}$ & & & & & 0.710 \\
\hline \multicolumn{2}{|c|}{ results of the matches } & & & & & \\
\hline
\end{tabular}

The value of " $t$ " Tabulated at $(0,05)=0.433$ 
Seen from the table (24)

and the existence of D. statistical correlation at level (0.05) between the psychological variables under consideration (emotional arousal and behavior of competition and self-efficacy and physical skills) and the results of matches at the table tennis players.

\section{Discuss the results:}

Evidenced by the results in search of Racquet Sports Games and their relationship to the level of arouse

an emotional and effective self-physical and effective self-skill as both a table (16), (17) that the average ranking of arousal emotional for my players tennis games in question, according to the type of activity came to hockey players and tennis Finally, table tennis, Reached the arithmetic average arousal emotional player field hockey Scale (123.89), and the standard deviation (9.24) and the value of the torsion coefficient (0.929), as can be seen that the SMA to measure arousal emotional (the behavior of Competition) players field hockey (106.28), and the standard deviation (1.43) and the value of convolution coefficient (0.335).

Researcher and explain the increase of the values of the arithmetic average and standard deviation and coefficient torsion of hockey players in the level of emotional arousal under discussion that most of the performance of sports skills hockey requires the performance aspects of knowledge legally in performance as well as to avoid hockey player to fall foul of the law during the performance in the matches less than other Racquet Sports Game sunder discussion and it could be due to the difficulty of performing the skills of hockey and the nature of the direct contact with competitors during the matches, may be attributed to a sense that while the defense and attacking or sense of danger or friction during the Competition with a stick hockey's biggest mistake and excitation more about sports and other racquet games under discussion rendering results are also higher for hockey players.

Researcher and explain those results to the hockey playground area a collective as 
a game and confront difficult situations in the matches as a position penalty stroke or penalty corner and expectations imposed and dumped psychological demands and take personal responsibility for achieving the desired objectives and therefore the high level of selfefficacy Compared to the sport of tennis and table tennis in the positions of confrontation and competition for the ball or play in different positions during the games, which is reflected on overstocked and overlapping players competing between defense and attack, the goal of scoring, especially from inside shooting circle ,

As it can be seen that the arithmetic average of the scale of self-physical players the effectiveness of field hockey (56.81), and standard deviation (2.12) and the value of convolution coefficient (0.205 ), and that the average value of the arithmetic mean of the effectiveness of selfefficacy skills has reached (89.53), and standard deviation (1.42) and the coefficient of torsion ( - 1.159).

And it explains the researcher those results to that stadium hockey

area collectively as a game and face difficult situations in the games as a position punitive strike or kick strikes penal and expectations imposed and placed psychological demands and take personal responsibility for achieving the desired objectives and therefore the high level of selfefficacy compared to the sport of tennis and table tennis in the positions of confrontation and competition for the ball or play in different positions during the games, which is reflected on the stack and overlap players to compete between the defense and attack the goal of scoring, especially from within the correction department

Thus summoned the physical self-efficacy combined with self-efficacy skills of the players from other hockey rest racquet Sports Games, as well as what might hurt the player pessimistic dimension of in the interpretation results and the wrong perception if failed, And misjudgments competitor during stressful situations attitudes of the penalty corner and penalty stroke which makes such attitudes show the importance of changing the wrong conceptions that afflict 
player arousal and its association to the rest of the positions of the match anxiety and the tension due to the multiplicity of stressful attitudes and not Players ability to control and confidence in performance under a plurality of such situations And has the ability to get out of the gloom to concentrate on collective play until the team can get out of playing restricted areas (inside the 16-yard area And Shooting inside the circle)

Which causes constant pressure in the previous dimensional in favor of hockey players as well as differences in the total level and the degree of self-efficacy(Physical and skill) for such attitudes in the restricted areas in hockey the way to get one difference on the penalty corner or penalty stroke, which increases the sense of the player self its efficiency-causing increased rates of scoring goals when entering the circle that the player scored the goal of which is calculated legally correctly goal.

This means that the more the opportunity to participate in sports activities And the friction and overlap in the area of the player with increased competition variables increased accordingly arousal factors And the greater therefore also the proportion of easy excitement the players

Should they have the ability of self-effectively to control the arousal emotional and direct, especially when they realize the difficulty of the competition gradually directing the degree of self-efficacy for players occasion of the limits of their level And their potential physical and skill and fit challenged their abilities, And can help the players to achieve that when we allow them to participate in the near the experimental competitions their level of their physical abilities And skill.

The results of the tennis players to the emotional arousal scale average scale (101.80), and the value of the standard deviation (6.56), Convolution coefficient value (0.086), as evidenced by the arithmetic mean of emotional arousal scale (the behavior of the competition) for tennis players (99.27), and the standard deviation (3.49) and the value of convolution coefficient (-0.369)

Researcher and explain that tennis players Due to the 
positions of the pressure And emotional arousal And careful not to lost points especially multiplicity of negative thinking errors.

In the intervening positions of points which may cause frequent errors during the competition and thus the loss of points, which makes tennis players often is the process of projection.

External for racket and the resurrection of the change it causes in continuous during the match and here we can say that when mastered tennis player skills and become the correct responses.

Is the dominant response (prevailing) has, the higher the intensity of arousal leading to the launch of the correct responses and thus have a direct output improved performance.

As it is clear that the arithmetic average of the scale of the physical self-tennis players efficiency (63.10) and the value of the standard deviation (4.41) and the value of convolution coefficient (1.140).

And the average value of the arithmetic mean of the effectiveness of self- skill has reached (95.07), and the standard deviation (3.58) and the value of convolution coefficient (1.197).(Attribute researcher results of selfefficacy (physical - and skill) of tennis players to time-out for players between rounds, which helps to keep relaxed physical and mental alertness of the players. If the player in a state of complete relaxation it becomes less likely to Attention deficit and to emotional arousal negative.

But if the player had a the tension, that negatively affects the ability to concentrate, as the body relaxed and alert mind during the timeout able to reclaim their self-efficacy physical or technical skills required nuances which prepares the optimal conditions for the fluency experience during the games.

Attribute researcher
results of self-efficacy
(physical - and skill) for tennis
players Ground to time-out for players between the circuits, which help to keep relaxed physical and mental alertness of the players. If the player in a state of total relaxation it becomes less likely to distract and to provoke negative emotional, but if the player has the tension, it negatively 
affects the ability to concentrate, as the body relaxed and alert mind during the timeout able to reclaim their self-efficacy or physical skills and their levels selfefficacy physical and skill than optimal conditions for the fluency experience during the games.

As for table tennis players measure of emotional arousal, the average scale (81.48), and the standard deviation (6.65) and the value of convolution coefficient (0.903 ), as evidenced by the arithmetic average to measure emotional arousal (competition behavior) for table tennis players (84.76), and the standard deviation (3.73) and the value of convolution coefficient (1.039).

$\mathrm{He}$ attributed the researcher also having differences statistically function for table tennis players through at least the results from other racket sports games under space And spatial space for competition.

Makes them are able to control the performance in speed and reactions that are reflected on the proficiency as well as the reaction speed that characterize the sport of table tennis skills and transition speed of the player depends very much on the his experience and expect to take the right place expected the fall of the ball, the exact technical performance of the skill of his great merit in influencing the degree of emotional arousal, especially for Competitive behavior.

All other sports, the most important is to help the players to Realize that the challenge is to not win the game and win-win results, but more importantly that each player achieves performance targets Personal do and that he must during the challenge of emotional arousal and directed to the positive trend when placed realistic goals, the challenge of self-effectiveness be close to the current level of abilities the player.

As it can be seen that the SMA to measure self-physical table tennis players efficiency (50.19), and the value of the standard deviation (3.33) and the coefficient of convolution (- 1.707) and that the average value of the arithmetic mean of the effectiveness of self-skill has reached (84.14), and the standard deviation (2.52) and 
the value of the torsion coefficient (-2.011).

And increase self for table tennis players and the effectiveness of psychological covered by performance improvements of the player and increase the experience and self-confidence is a positive effect some skills variables that include reaction speed and power of the blow, speed and correct and therefore increase the percentage of achievement in performance, and the successful advice and motivation provided by the trainer for the player and the circumstances surrounding a big role in increasing the skill performance during the match, so "The trainer successful is skillful in organizing the energies of the physical and psychological players and how to manage and control the thoughts and feelings of his players during the competition which makes the performance developing toward the right.

Good

arousal (excitement) dissipates all the anxiety and tension that accompanies in important matches as the "excitement optimal rate leads to behavior and effective performance".
The foregoing enables a researcher from the following:

Ability to recognize the relationship and the comparison between the scores of emotional arousal for each of my sport hockey

Tennis, table tennis and all of their grades also in selfefficacy and physical skills.

1- Comparability of statistical values arousal emotional each of my sport hockey and tennis. Table tennis and all of their grades also in self-efficacy and physical skills.

2- Possession hockey player's Emotional arousal high of more than tennis players Ground.

3- Possession of hockey players with less skill decrease in positions of confrontation and competition for the ball or play in different positions during matches, which occur by the overcrowding and overlapping of players to compete for tennis players.

4- There inverse correlation between self-skills and emotional arousal and exceeded the optimum sample rate determinants. 
The relationship between negative emotional arousal and self-skills and the reason for this is due to several factors including the emotional arousal, may rise for optimal borders rate among hockey players because of direct contact in performance, especially in matches with the high-level competitive and convergent between the competing teams, thus affecting the performance of the player as "there is an inverse relationship statistically significant in the degree of emotional arousal and performance skills at the level of the player any player should be prepared for the players Racket sports games to prepare myself well can achieve through good excitability and achieved good performance Skill and effective and, but Conversely may happen ,also this control depends on the player experience as the "sports experience an important and effective role in controlling emotional cases unwanted before matches and the competition "As the emotional excitability availability a good level helps to achieve excellent performances skill, the trainer tries to create an atmosphere the relatively weak arousal and anxiety low arousal levels than the junior player's chances of successful performance and the experience of success but in turn bolster self-confidence

Perhaps the biggest motivation to contribute to theory appears to interpret the relationship between learning and arousal and also between performance and arousal many of the junior players because they are preparing skilled competitors in their sports, although the effect of arousal varies from teenager to a skilled player perhaps the biggest motivation to contribute to theory appears to interpret the relationship between learning and arousal, as well as between performance and arousal many of the junior players because they are preparing skilled competitors in their sports, although the effect of arousal varies from junior to a skilled player and refers the search results to the agreement implicit practical applications of theory the inverted $U$ in the sports field to it: the level of arousal required high in the Motor Activities, which require large muscle work, and low in 
motor activities that require fine muscle work (small), and that each sports skill optimal level of arousal

It is through what has been achieved stated hypotheses in a relationship between emotional of arousal and self-skills but this of arousal must be in the level can be tapped and is effective player in the performance of skill and is done through a good psychological preparation by the trainer during the training period and to accustom the player On how to cope with difficult circumstances and without nervous controlled for the take advantage of these of arousal positively to raise the skill level and achieve a good achievement for the team The effectiveness of self-represent a behavior and a knowledge mediator between my sport of tennis, hockey player because they expect of self-efficacy in the sport of tennis, specified by the disposal of the player's performance individually itself, and the nature and extent of act and behavior of the performance they'll be doing and the extent of the effort that his will to face the problems and not all related to the collective performance as hockey sport or to abstain from which affects the behavior of the competition and the initiative and perseverance he has in the game. In critical and difficult and the degree of perseverance that will appear in the face of problems or difficulties encountered situations and then the selfefficacy influence the decision to the player in a personal capacity and not all related to the collective performance as hockey sport or to abstain from which affects the behavior of the competition and the initiative and perseverance he has in matches.

\section{Conclusions}

and

\section{Recommendations:-}

\section{Firstly and conclusions.}

In the light of the objectives and research hypotheses marked by the researcher concluded the following questions.

1- The degree of emotional arousal to the players some Racquet games was their ranking Descending Direction hockey and tennis and table tennis respectively.

2- The degree of self-efficacy (physical) among players some Racquet games (tennis satisfied - Hockey - Table tennis) 
Likewise the degree of selfefficacy (skills) to the players some Racquet games have been their ranking (tennis satisfied - hockey - table tennis), respectively.

3- There are no significant differences in the degree of emotional of arousal between the players some Racquet hockey games - tennis - table tennis, which shows that the emotional arousal and one of the players in different sports Racquet games.

4- There are no differences in the degree of self-efficacy (physical) between the players some sports Racquet games (Hockey - Tennis - Table Tennis), as well as there are no differences in the degree of self-efficacy (skills) between the players some sports Racquet games (Hockey Tennis - Table Tennis ), but no statistically significant difference between sports Racquet games research sample (hockey - tennis - table tennis) the effectiveness of the self (physical - skills)In less significant difference for the emotional arousal physical value.

5- There is a direct correlation between emotional of arousal and behavior of the competition and the effectiveness of selfrelationship of (physical - skill) and the results of matches of the Racquet players in some sports games (hockey - Tennis - table tennis).

\section{Recommendation:-}

In light of the findings, which were based on the nature of the research, the sample and the method used and guided by the results deduced researcher recommend the following:

1- Scales use of search as a method by coach to see what owned the players of raising self-efficacy skills and physical self-efficacy periodically.

2- Attention of the trainer beside the psychological preparation for the player for the level of emotional of arousal and performance skills and make them as good as that achieves high levels of the players control.

3- Take advantage of research in improving the level of emotional of arousal to the players and to be unaffected the outcome of cases of failure that affect level of performance the player.

4- Adoption of one of methods

psychological

guidance to players to reduce 
the degree of emotional of arousal and make it as good as after the end of the warm-up and the beginning of the competition.

5- Subjecting players to some strong games that are characterized by the high level and the converging and characterized by Subscribe and compete in matches and competitions to add experience to the players to counter the psychological stress.

6- The need for successive studies broadly similar to unravel the relationship between emotional arousal and self-efficacy and performance results in the rest of the other games.

7- Interest in the different causes of emotional excitability during various games Racquet games and note the actual positions of the matches and the extent of conformity by the results or performance.

8- Comparative studies to identify the reasons and explanations known as effectiveness self and the results of the distinctive behavior or performance and its relationship to the results in the different games. In the domain sports and interest in conducting more research concerned with studying the self-confidence, as one of the important in the field of sports psychological skills, and their relationship to other psychological variables.

\section{References used:-}

1- Ahmad Amin Fawzi: the principles of sports psychology; concepts and applications, i, 1st Edition, Dar Al fikr al Arabi, Cairo, 2003.

2- Ornov: (advances in psychology), Adel Ezzedine translation and others, Cairo, Al-Ahram printing house, 1983.

\section{3- Osama Kamel ratreb:} Sports Psychology (concepts and applications), the first edition, Cairo, Dar ATF, 1995.

4- Osama Kamel rateb : the psychology of sport, the first edition, Cairo, Dar ATF, 1997.

\section{5- 6. Osama Kamel rateb:}

(psychological skills training applications in the field of sports), 2nd Floor Cairo, Dar the Arab Thought 2004.

6- Abdul

Mohammed

Rahman Psychophysiology, a study in the interpretation of human behaviors, Beirut, Dar Al Nahda for Printing and Publishing, 1991. 
7- Abdul Karim, Mohamed

Mahmoud Hamdi: emotional arousal and its relationship with some physiological variables and performance skills in volleyball, Scientific Conference (human development among the challenges and ambitions), Faculty of Physical Education for Boys, Helwan University, Cairo, 1996.

8- Abdul

Wahab

Mohammed al-Najjar: Sport psychology Department of Physical Education and Movement Sciences at King Saud University (arousal and anxiety in athletes)

9- Awatef Saleh Hussein : "self - efficacy and its relationship with the pressures of life among young university," Journal of the Faculty of Education, Mansoura University .aladd (23), (1993))Bandura (known as Pandora,

10- Qassim Hassan Hussein : Encyclopedia of sports and physical Games overall actors sports sciences: Amman, Dar es Salaam thought for printing, 1998.
11-Mohammad

Hassan

Allawi: Entrance in sports psychology, the first edition, Cairo, the center of the book for publication, 1998.

\section{2-Mohammad}

Hassan

Allawi: Encyclopedia of psychological tests for athletes, 1st Floor, Cairo, Dar ATF, 1998.

\section{3-Mohammad Hassan}

Allawi, Mohamed Nasr elddin Radwan: psychological and skill tests, Cairo, Dar ATF, 1987.

14- Mohamed Abdel Salam: educational and psychological measurement, the first edition, Cairo, Egyptian Renaissance Library, 1988.

\section{5-Bandura, A. (1986):} Social foundations of thought and action: a social cognitive therapy. N.Y. Englewood cliffs. Prentice. Hall Inc.

16- Bandura, A. and Wood, R. (1989) : Effect of perceived controllability and performance standards on Self- Regulation of complex Decision making. Journal of personality and social psychology Vol. 56.No. 5. 